\title{
Evaluation of Trichoderma as a biological control against different pathogenic bacteria and fungi
}

\author{
Mallalai Ali Shah ${ }^{1}$, Hamida $\mathrm{Ali}^{1}$, Inam ul Haq ${ }^{2}$, Imran Shah ${ }^{2}$, \\ Muhammad Naeem ${ }^{3}$, Abdul Samad ${ }^{3}$, Zubaida Sher ${ }^{1}$ and Tauseef \\ Muhammad Asmat ${ }^{3 *}$ \\ 1. Department of Zoology, Sardar Bahadur Khan Women's University, Quetta-Pakistan \\ 2. Department of Plant Pathology, Pir Mehr Ali Shah Arid Agriculture University Rawalpindi-Pakistan \\ 3. Center for Advanced Studies in Vaccinology and Biotechnology (CASVAB), University of Balochistan \\ Quetta-Pakistan \\ *Corresponding author's email: tauseefcasvab@gmail.com \\ Citation
}

Mallalai Ali Shah, Hamida Ali, Inam ul Haq, Imran Shah, Muhammad Naeem, Abdul Samad, Zubaida Sher and Tauseef Muhammad Asmat. Evaluation of Trichoderma as a biological control against different pathogenic bacteria and fungi. Pure and Applied Biology. Vol. 9, Issue 1, pp1223-1229.

http://dx.doi.org/10.19045/bspab.2020.90129

\begin{tabular}{llll}
\hline \hline Received: 22/11/2019 & Revised: 16/01/2020 & Accepted: 25/01/2020 & Online First: 07/02/2020 \\
\hline \hline
\end{tabular}

\section{Abstract}

Recently, the use of biological control agents (BCAs) gained immense popularity in different fields of biology, especially in pathology and entomology as an alternate approach to decrease the use of synthetic chemicals, thus reducing the environmental threats potentially dangerous to humans and the environment. This study was carried out to isolate Trichoderma from farmyard manure (FYM) and rhizosphere of plants. These isolates were successfully identified macroscopically and microscopically. The biocontrol activity of these Trichoderma isolates were evaluated in vitro against pathogenic fungi (Fusarium oxysporum, Alternaria alternata) and bacteria (Pectobacterium carotovorum, Pseudomonas syringae). Biocontrol efficiency against these pathogens was performed by dual culture technique and the inhibition percentage and radial growth percentage of pathogens were calculated. In vitro results showed that Trichoderma species showed effective biocontrol activity against all tested pathogens i-e $P$. carotovorum, $P$. syringe, $F$. oxysporum, and A. alternata, with inhibition percentage of $91.7 \%$, $91.7 \%, 80 \%$ and $75 \%$, respectively. The least radial growth in the presence of Trichoderma isolates was shown by $P$. carotovorum (8.3\%) and P. syringae (8.3\%) followed by $F$. oxysporum (20\%) and $A$. Alternata $(25 \%)$. Trichoderma species played a vital role in controlling all the tested pathogens. However, their biocontrol activity against $P$. carotovorum and $P$. syringae was found to be higher than other pathogens. This study showed the potential of Trichoderma species as a biocontrol agent and it needs to be confirmed through in vivo applications in the future. This control method is safe, cheap and eco-friendly and has no hazard to human and environment.

Keywords: Biocontrol; Dual culture technique; Inhibition percentage; Trichoderma

\section{Introduction}

Bacterial and fungal pathogens cause infections in plant and animal hosts. These pathogens can cause disease on a narrow and also at wide ranges of hosts. However, some have a dual ability to cause diseases in different hosts [1]. Use of traditional control methods are not eco-friendly approach and also produce different aromatic group or ethylated and methylated substances which have adverse effects on the environment and also pose a risk to human health via water contaminations, foodstuff or accidental exposure. Therefore, efforts were made to use biological control method for controlling 
the pathogens in the eco-friendly way which are safe both for humans and as well as for environment [2].

The term biological control and its alternative expression biocontrol have been used in different fields of biology, most remarkably for pathology and entomology [3]. In each field of biology, the use of animal, fungi and/or other microbes to feed upon, parasitize, suppresses or otherwise interfere with targeted pathogens is referred to as the biological control agents (BCAs) [4]. Furthermore, these agents seek to renovate the beneficial balance of natural ecosystem [5].

Biological control method is only wellknown when BCAs can effectively accomplish the interaction between the pathogen and host. Currently, several fungal and bacterial BCAs have been recognized. The fungal agents include Trichoderma, Rhizoctonia, Candida, and Coniothyrium [6] and bacterial agents Agrobacterium and Bacillus [7]. Among these BCAs Trichoderma is the most important biocontrol agent which has been used for controlling pathogenic bacteria and fungi [8]. Trichoderma species are typically anaerobic, facultative and cosmopolitan that can be commonly found in greater number in animal manures, organic compounds, soil, in other substrates such as decaying wood and rhizosphere of plants [9, 10]. Furthermore, some organisms also lead to isolation of Trichoderma from unexpected sources, such as cockroaches [11], shellfish marine and mussels [12] and from guts of termite [13]. Trichoderma are characterized by rapid growth, generally green conidia and branched conidiophores [14]. They belong to the subdivision Deuteromycetes and do not have determinate sexual forms, as the majority of strains are modified to asexual states [15].

The researchers reported that the Trichoderma species is considered to be eager and good colonizers and mainly invasive fungi and they also work against pathogens either indirectly by challenging for space and nutrients, adjusting environmental conditions or stimulating antibiosis and host defensive mechanisms, or directly by mycoparasitism. The Trichoderma species have growth inhibiting property of other parasites due to their joint activity of numerous enzymes together with the ability of Trichoderma to produce diverse secondary metabolites. Moreover, Trichoderma species prompts systemic and local defence in hosts [15, 16]. Many scientists also reported that the Trichoderma species have antagonistic activity against Ascomycetes, Basidiomycetes, Deuteromycetes fungi and various types of prokaryotes [17]. In this study we focused on $F$. oxysporum, $A$. alternata, $P$. carotovorum and $P$. syringae because these pathogens have a wide range of hosts which affect them adversely. The control of these pathogens by means of Trichoderma is an eco-friendly method and safe for human and environment.

\section{Materials and methods Sample collection}

A total of 10 samples were collected to assure the presence of Trichoderma species from different collection sites of Pir Mehr Ali Shah Arid Agriculture University Rawalpindi (PMAS-AAUR) and from Zhob, Balochistan. Eight of the samples were collected from farmyard manure (FYM) and two from the rhizosphere of plants. The samples were collected in sterile plastic bags and were properly labelled to indicate the location sites and collection date. Then, the samples were brought into the department of Plant Pathology of PMAS-AAUR, Pakistan for further analysis.

\section{Isolation of Trichoderma species}

Serial dilution method was used to analyze the collected samples. First the collected samples were homogenized and then $1 \mathrm{~g}$ of the samples were weighed and used to do serial dilution for the isolation of Trichoderma species. One gram of sample was properly blended into $10 \mathrm{ml}$ of sterile water then $1 \mathrm{ml}$ of suspension was taken into another tube containing $9 \mathrm{ml}$ of sterile 
water. The serial dilution technique was performed up to $10^{-3}$ to $10^{-4}$. At that point, $100 \mu 1$ suspension of each diluted sample was transferred onto Potato Dextrose Agar (PDA) plates and spread carefully by using a spreader or sterilized glass. The plates were then stored at $28-30^{\circ} \mathrm{C}$ for a week. The plates were checked daily and observable colonies were transferred to new PDA plates and incubated at $28-30^{\circ} \mathrm{C}$ for one week.

\section{Identification of Trichoderma isolates}

The identification was performed by observing both microscopic and macroscopic features of the Trichoderma colonies. For microscopic study, mycelia from each colony were taken from PDA petri plate and spread on the top of a slide having a drop of sterile water and examined the slide under a microscope using 400X magnification power. The sizes and shapes of conidia, conidiophores and phialides were studied. For macroscopic study, the colour and growth rate of the fungal colonies were observed. The microscopic and macroscopic features were associated to the characteristics of Trichoderma as reported by Samuels et al. [18].

In vitro evaluation of Trichoderma isolates against test pathogens by dual culture technique

Trichoderma isolates were evaluated in vitro for their biocontrol efficiency against fungal and bacterial pathogens viz., $F$. oxysporum, A. alternata, $P$. carotovorum and $P$. syringae by dual culture method. These pathogens were provided from the department of Plant Pathology of PMASAAUR, Pakistan. First of all, approximately $20 \mathrm{ml}$ of PDA media for fungi and nutrient agar (NA) media for bacteria were poured in petri plates. When media were solidified, a $5 \mathrm{~mm}$ diameter disc from the edge of 3-4 day old culture of Trichoderma colony and the test pathogens were positioned on the opposite side of the petri plate at equivalent space with the help of sterile cork borer. Later these plates were closed with Para film under sterile conditions. Petri plates having only test pathogen and without Trichoderma species served as control plate. There were three replications for each pathogen. The whole process was done in a sterile condition and both the test plates and control plates were stored at $28^{\circ} \mathrm{C}$ for one week. The colony of the test pathogen was measured after first, second, third and fourth days of the incubation. Finally, the percent (\%) inhibition growth was measured in relation of growth in control plate [19].

$\mathrm{I}=\frac{\mathrm{C}-\mathrm{T}}{\mathrm{C}} \times 100$

Where,

$\mathrm{I}=\%$ inhibition of growth

$\mathrm{C}=$ growth in control plate $(\mathrm{cm})$

$\mathrm{T}=$ growth in test plate $(\mathrm{cm})$

\section{Results}

\section{Isolation and identification of Trichoderma species}

Trichoderma isolates were successfully isolated from four samples out of 10 different samples. Three isolates (Ma1, Ma3 and Mz1) were from the FYM while one isolate (Ma6) from rhizosphere of plant. All the Trichoderma isolates grew faster and produced conidia within a week. Conidial growth of Ma1 was scattered, clustered, green colored and produced concentric rings. The dispersed, fast growth rate and yellowish colonies were observed in Ma3 and Ma6, respectively. While in Mz1, the colour appeared to be dark green. All the Trichoderma isolates except Mz1 fully covered the $9 \mathrm{~cm}$ Petri plates in a week. The isolate Ma1 had branched conidiophore, paired phialides, broader and rough shaped conidia. Both Ma3 and Ma6 had minute conidiophore and rough shaped conidia. However, the isolate Mz1 had only branched conidiophore, phialides while conidia were not observed (Figure 1).

Besides these characteristic, Samuels et al. [18] reported that the colonies of Trichoderma produced coconut like odour which can be also the characteristic of that species. In present study isolate Ma1 produced an odour close to coconut. 


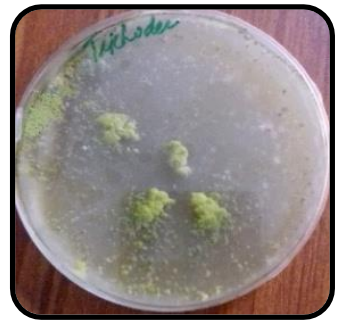

a.

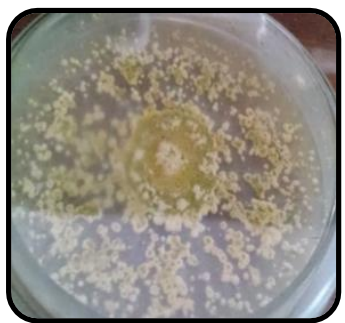

b.

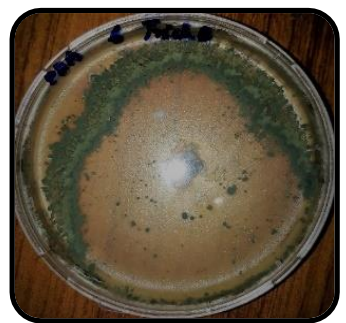

c.

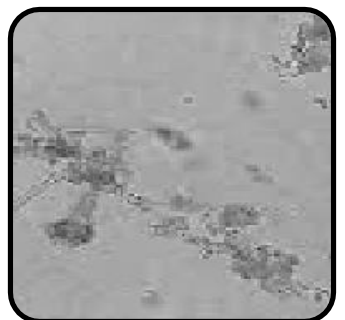

d.

Figure 1. Macroscopic and microscopic observations of Trichoderma isolates. (a) Isolate Ma1 (b) Isolate Ma3 (c) Isolate Mz1 (d) Microscopic observation of isolate Ma1, branched conidiophore, paired phialides and rough conidia.

In vitro evaluation of Trichoderma against fungal pathogens

The Trichoderma isolates were screened in vitro against $F$. Oxysporum and A. alternata by dual culture technique on PDA media for one week. Data were recorded every day and at the end of the week the antagonistic activity of Trichoderma isolates showed more influence against the growth of test pathogens.

The Trichoderma isolates showed great inhibition activity against the growth of $F$. oxysporum which had $1 \mathrm{~cm}$ growth as compared to $5 \mathrm{~cm}$ in control plate. The Trichoderma isolates inhibited the growth of $F$. oxysporum by $80 \%$. Whereas the growth of $A$. alternata was $1 \mathrm{~cm}$ as compared to $4 \mathrm{~cm}$ growth in control plate. The Trichoderma isolates inhibited the growth of A. alternata by $75 \%$. The redial growth of $F$. oxysporum and $A$. alternata in the presence of Trichoderma isolates were calculated as $20 \%$ and $25 \%$, respectively (Figure $2 \& 4$ ).

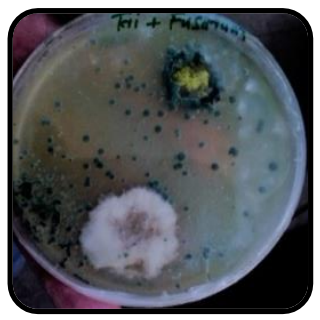

a.

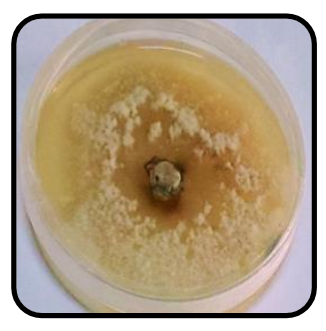

b.

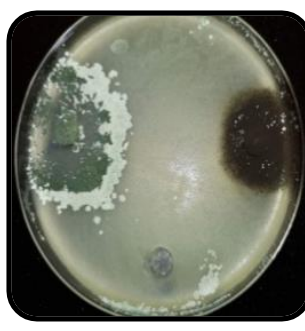

c.

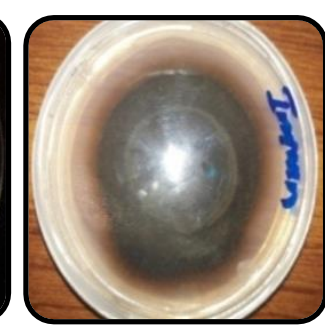

d.

Figure 2. In vitro evaluation of Trichoderma isolates against fungal pathogens by dual culture technique. (a) Trichoderma isolate showing biocontrol efficiency against $F$. oxysporum. (b) Growth of $F$. oxysporum in control plate. (c) Trichoderma isolate showing biocontrol efficiency against $\boldsymbol{A}$. alternata. (d) Growth of $\boldsymbol{A}$. alternata in control plate.

In vitro evaluation of Trichoderma against bacterial pathogens

The Trichoderma isolates were screened in vitro against $P$. carotovorum and $P$. syringae by dual culture (zig zag) technique on NA media for one week. Data were recorded every day and at the end of the week the antagonistic activity of Trichoderma isolates showed more influence against the growth of test pathogens.
Trichoderma isolates showed greatest performance against the growth of $P$. carotovorum which had $0.5 \mathrm{~cm}$ growth as compared to $6 \mathrm{~cm}$ in control plate. Trichoderma inhibited the growth of $P$. carotovorum by $91.7 \%$. Whereas the growth of $P$. syringae was $0.5 \mathrm{~cm}$ as compared to $6 \mathrm{~cm}$ growth in control plate. The Trichoderma isolates inhibited the growth of $P$. syringae by $91.7 \%$. The redial growth of both $P$. carotovorum and $P$. 
syringae, in the presence of Trichoderma isolates was $8.3 \%$ (Figure $3 \& 4$ ).

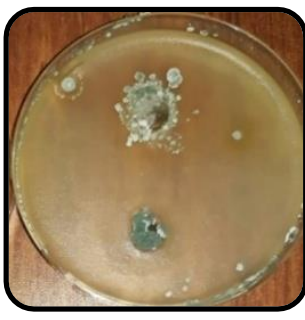

a.

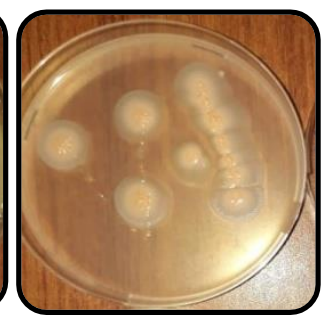

b.

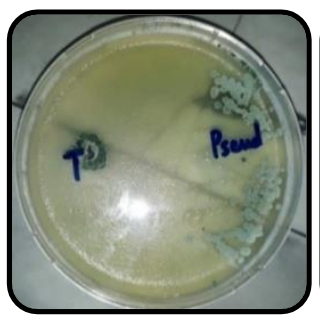

c.

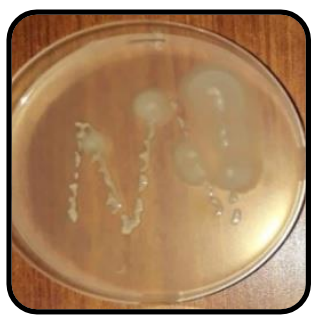

d.

Figure 3. In vitro evaluation of Trichoderma isolate against bacterial pathogens by dual culture (zig zag) technique. (a) Trichoderma isolate showing excellent biocontrol efficiency against $P$. carotovorum. (b) Growth of $P$. carotovorum in control plate. (c) Trichoderma isolate showing excellent biocontrol efficiency against $P$. syringae (d) Growth of $P$. syringae in control plate

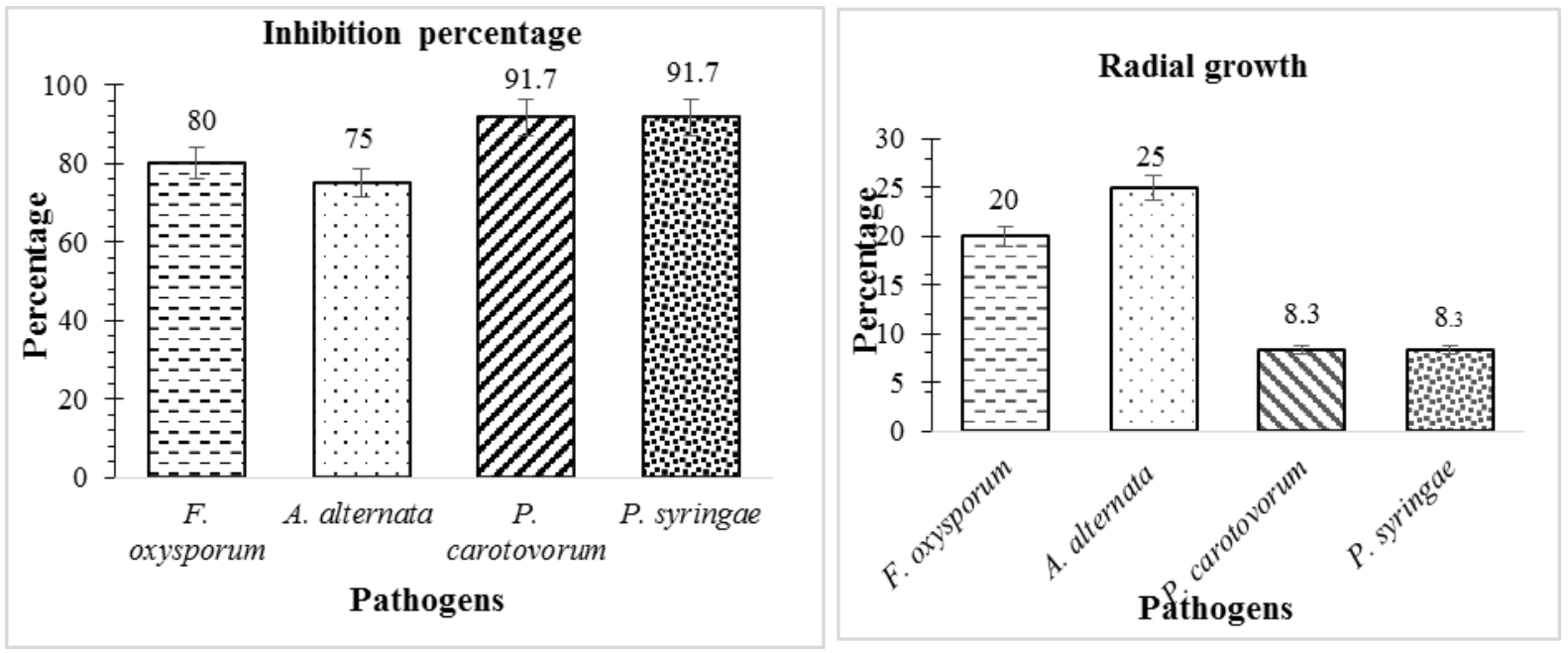

a.

b.

Figure 4. Inhibition and radial growth percentage of fungal and bacterial pathogens in the presence of Trichoderma isolates (a) Bar chart showing the inhibition percentage of tested pathogens (b) Bar chart showing the radial growth percentage of tested pathogens

\section{Discussion}

Biocontrol is a promising and effective method to keep up the current level of the agricultural products by limiting the release of chemical pesticides to the environment and as well as making the plants free from pathogens. Biocontrol method is only well known when the BCAs can effectively accomplish the interaction among the pathogen and host. Plant pathogenic bacteria and fungi are the widespread problems and the utilization of synthetic chemical substances is not really effective. According to this study, biocontrol method has been found useful and is a better alternative against fungal and bacterial pathogens such as F. oxysporum, A. alternata, $P$. carotovorum and $P$. syringae. One of the main advantages of biocontrol method is that these alternatives are much safe, cheaper and environment friendly control method against pathogens and have no hazard to human and environment.

Currently, several fungal and bacterial biocontrol agents have been recognized for controlling the pathogens such as Trichoderma, Candida, Rhizoctonia, Coniothyrium, Bacillus and Agrobacterium [6,7]. Among these, one of the fungal BCAs used in present study is Trichoderma species, they are saprophytic fungi that can commonly found everywhere 
including decaying plant material, rhizospheres of plants and as well as in animal manure. The reason for selecting Trichoderma species as BCA is their potential to decrease the incidence of diseases caused by the tested pathogens. The mechanisms of antagonism used by Trichoderma species include competition for nutrients and space, inhibitory compounds and antibiosis by processing non-volatile antibiotics and volatile components that suppress parasitism as well as for soilborne fungi. Trichoderma species reduce the infections caused by the pathogens by various mechanisms such as antibiosis, secretion of enzymes, mycoparasitism, competition and hyphal interactions [20].

In this study, the results of in vitro inhibitory efficiency of Trichoderma isolates against $F$. oxysporum, A. alternata, $P$. carotovorum and $P$. syringae were studied by dual culture technique. Three replication of Trichoderma isolates were used during this technique for the calculation of inhibition and growth percentage of respective pathogen for a reliable result. The antagonistic activities of Trichoderma isolates were found to be very effective against these test pathogens.

Significant results were obtained when Trichoderma isolates formed zone of inhibition against these fungal and bacterial pathogens though with variations. The maximum zone of inhibition was formed against bacteria $P$. carotovorum by $91.7 \%$ and $P$. syringae by $91.7 \%$ followed by fungus $F$. oxysporum by 80\%.Whereas Trichoderma isolate formed the minimum inhibition zone against $A$. alternata by $75 \%$. However, the results showed that the inhibition activity of Trichoderma isolate was higher against all tested pathogens but the gowth of $P$. carotovorum, and $P$. syringae were controlled the most.

There are several data reporting the biocontrol activity of Trichoderma species against $A$. alternata, Phytophthora, Pseudomonas, Rhizopus and Pythium [21]. Some researchers also reported that Trichoderma species being a biocontrol agent have shown good results against different pathogens such as Fusarium oxysporum, Rhizoctonia solani, Pythium aphanidermatium, Phytophthora cactorum and Alternaria species $[9,22]$. Our findings are in agreement with the study by Rahman [23] who reported that Trichoderma species inhibited the growth of $F$. oxysporum by $81 \%$ and $83 \%$, respectively. Similarly, Bardia and Rai [24] reported that Trichoderma species inhibited $F$. oxysporum growth by $51 \%$ and $58 \%$. Nowadays the biological control methods are based on fungus Trichoderma species. Therefore, this fungus has drawn much attention as a biocontrol agent.

\section{Conclusion}

It is concluded that Trichoderma reduced the growth of all four pathogens i-e $F$. oxysporum, $A$. alternata, $P$. carotovorum and $P$. syringae significantly at different levels. Thus, this species can be a better choice to control different types of pathogens and can be included for integrated disease management of plant pathogens. Their efficiency against bacterial pathogens such as $P$. carotovorum and $P$. syringae was found to be higher in contrast to fungal pathogens. Consequently, this BCA can have effective results in agricultural fields to protect the plants from various bacterial and fungal pathogens.

\section{Authors' contributions}

Conceived and designed the experiments: IU Haq, TM Asmat, Performed the experiments: MA Shah, Z Sher, Analyzed the data: H Ali, Contributed materials/ analysis/ tools: $M$ Naeem, A Samad, Wrote the paper: I Shah.

\section{References}

1. Ortoneda M, Guarro J, Madrid MP, Caracuel Z, Roncero MIG, Mayayo E \& Di Pietro A (2004). Fusarium oxysporum as a multi host model for the genetic dissection of fungal virulence in plants and mammals. Infect Immun 72(3): 17601766.

2. Osman MEH, EL-Sheekh MM, Metwally MA, Ismail AEWA \& Ismail MM (2011). Antagonistic activity of some fungi and Cyanobacteria species against Rhizoctonia solani. Int J Plant Pathol 2(3):101-114.

3. Pal KK \& Gardener BM (2006). Biological control of plant pathogens. The plant health instructor 2: 1117-1142.

4. Lockwood JA (2000). Non target effects of biological control. Kluwer Academic Publishers. In P.A. Follett and J.J. Duan (eds.) Boston, Massachusetts. pp. 15- 30.

5. Cutler HG, Cutler SJ, Ross SA, Sayed KE, Dugan FM, Bartlett MG \& Parker SR (1999). Koninginin G, a new metaboli te from Trichoderma aureoviride. J Nat Prod 62(1): 137-139.

6. Mavrodi DV, Mavrodi OV, McSpaddenGardener BB, Landa BB, Weller DM \& Thomashow LS (2002). Identification of 
differences in genome content among phlD-positive Pseudomonas fluorescens strains by using PCR based subtractive hybridization. Appl Environ Microiol 68(10): 5170-5176.

7. Gilardi G, Manker DC, Garibaldi A \& Gullino ML (2008). Efficacy of the biocontrol agents Bacillus subtilis and Ampelomyces

quisqualis applied in combination with fungicides against powdery mildew of zucchini. J Plant Dis Protect 115:208213.

8. Yaqub F \& Shahzad S (2008). Effect of seed pelleting with Trichoderma spp. and Gliocladium virens on growth and colonization of roots of sunflower and mung bean by Sclerotium rolfsii. Pak J Bot 40(2): 947-953.

9. Harman GE (2000). Myths and dogmas of biocontrol. Changes in perceptions derived from research on Trichoderma harzianum T-22. Plant Dis 84(4): 377-393.

10. Irina D \& Christian PK (2004). Species and biodiversity in Trichoderma and Hypocera: from aggregate species to species clusters. J Zhejiang Uni Sci 6(2): 100-112.

11. Yoder JA, Glenn BD, Benoit JB \& Zettler LW (2008). The giant Madagascar hissing-cockroach (Gromphadorhina portentosa) as a source of antagonistic moulds: concerns arising from its use in a public setting. Mycoses 51(2): 95-98.

12. Sallenave-Namont C, Pouchus YF, Du Pont TR, Lassus P \& Verbist JF (2000). Toxigenic saprophytic fungi in marine shellfish farming areas. Mycopathologia 149(1): 21-25.

13. Sreerama L \& Veerabhadrappa PS (1993). Isolation and properties of carboxylesterases of the termite gutassociated fungus, Xylaria nigripes. K., and their identity from the host termite, Odentotermes horni. W., mid-gut carboxylesterases. Int J Biochem 25(11): 1637-1651.

14. Gams W \& Bissett J (2002). Morphology and identification of Trichoderma. In: Trichoderma and Gliocladium. Basic biology, taxonomy and genetics, Harman GE and Kubicek CP (Eds.).Vol. 1, Taylor and Francis, London, UK, pp 3-34.
15. Harman GE, Howell CR, Viterbo A, Chet I \& Lorito M (2004). Trichoderma species opportunistic, virulent plant symbionts. Nat Rev Microbiol 2(1): 43-56.

16. Yedidia I, Shoresh M, Kerem Z, Benhamou N, Kapulnik Y \& Chet I (2003). Concomitant induction of systemic resistance to Pseudomonas syringae pv. lachrymans in cucumber by Trichoderma asperellum (T-203) and accumulation of phytoalexins. Appl Environ Microbiol 69(12): 7343-7353.

17. Monte E (2001). Understanding Trichoderma: between biotechnology and microbial ecology. Int Microbiol 4(1): 1-4.

18. Samuels GJ, Chaverr P, Farr DF \& McCray EB (2002). Trichoderma Online. Systematic Mycology and Microbiology Laboratory, ARS, USDA; http://nt.arsgrin.gov/

taxadescriptions/keys/Trichoderma Index.cfm.

19. Hajieghrari B, Torabi-Giglou M, Mohammadi MR \& Davari M (2008). Biological potential of some Iranian Trichoderma isolates in the control of soil borne plant pathogenic fungi. Afr $J$ Biotechnol 7(8): 967-972.

20. Ponnusamykonar P, Venkitasamy K \& Varatharajan P (2011). In vitro study of antagonistic effect of Trichoderma sp., on tea plant pathogen, Phomopsis theae. Arch Appl Sci Res 3(4): 352-358.

21. Kucuk C \& Kivanc M (2004). Isolation of Trichoderma spp. and determination of their antifungal, biochemical and physiological features. Turk J Biol 27(4): 247-253.

22. Yi X, Ding W \& Li Y (2010). Antagonistic mechanisms of Trichoderma spp. against Phytophthora nicotianae. Zhongguo Zhong Yao Za Zhi 35(11): 1386-1390.

23. Rahman MM (2010). Studies on bacterial soft rot disease of potato and onion in storage and its management. A PhD thesis. Depart. Plant Pathol, Bangabandhu Sheikh Mujibur Rahman Agric. Uni., Gazipur, Bangladesh, pp 126.

24. Bardia PK \& Rai PK (2007). In vitro and field evaluation of biocontrol agents and fungicides against wilt of cumin caused by Fusarium oxysporum f. sp. cumini. J Spices Aromat Crops 16(2): 8892. 